\title{
Modeling the carbon and nitrogen cycles
}

\author{
Costas A. Varotsos ${ }^{1 *}$, Vladimir F. Krapivin ${ }^{2}$ and Vladimir Y. Soldatov ${ }^{2}$ \\ ${ }^{1}$ Laboratory of Upper Air/UoAthens Climate Research Group, Department of Environmental Physics and Meteorology, Faculty of Physics, University of Athens, \\ Athens, Greece \\ 2 Institute of Radioengineering and Electronics, Russian Academy of Sciences, Moscow, Russia
}

\section{Edited by:}

Yong Xue, London Metropolitan

University, UK

Reviewed by:

Eleni Drakaki, National Technical University of Athens, Greece

Deepak Jhajharia, North Eastern Regional Institute of Science and Technology, India

*Correspondence:

Costas A. Varotsos, Laboratory of Upper Air/UoAthens Climate

Research Group, Department of

Environmental Physics and

Meteorology, Faculty of Physics,

University of Athens, University

Campus, Bldg. Phys 5, Athens

15784, Greece

e-mail:covar@phys.uoa.gr
The issues of air pollution are inextricably linked to the mechanisms underlying the physicochemical functioning of the biosphere which together with the atmosphere, the cryosphere, the lithosphere, and the hydrosphere constitute the climate system. We herewith present a review of the achievements and unresolved problems concerning the modeling of the biochemical cycles of basic chemicals of the climate system, such as carbon and nitrogen. Although the achievements in this area can roughly describe the carbon and nitrogen cycles, serious problems still remain associated with the accuracy and precision of the processes and assessments employed in the relevant modeling.

Keywords: biochemical processes, carbon cycle, nitrogen cycle, modeling, greenhouse effect

\section{MODELING SCHEMES OF THE GLOBAL CARBON CYCLE}

It is generally recognized today that the complete understanding of the $\mathrm{CO}_{2}$ contribution in the formation of the atmospheric greenhouse effect presupposes a thorough examination of the biogeochemical dynamics of the carbon cycle (Kondratyev and Varotsos, 1995; Kondratyev et al., 2004; Krapivin and Varotsos, 2008; Amann et al., 2011). In the current literature a lot of schematic pathways of carbon cycle are considered in the form of global $\mathrm{CO}_{2}$ changes. Herewith we refer to the most important ones, demonstrating their main characteristics in order to understand the limits of the simulation of the carbon cycle compounds. It should be worthwhile to note that all the assumed pathways of the $\mathrm{CO}_{2}$ cycle on a global scale are often separated into two groups, notably: point wise (averaged on a global scale) and spatial (averaged on a local scale). All these schematic pathways consider that the biosphere is consisting of three ecosystems, viz., atmosphere, oceans, and land. In addition, a number of the available schematic diagrams of the carbon cycle distinguish the organic from inorganic types (Kondratyev et al., 2004). Moreover, the temporal averaging of all carbon processes and reservoirs is often performed on an annual basis, and thus the atmosphere is regarded as an homogeneous medium (point-wise). In this investigation the World Ocean and the surface ecosystems are based on global data bases for the carbon reservoirs. In general, these diagrams describe the atmospheric $\mathrm{CO}_{2}$ concentrations assuming a typical scenario for the anthropogenic activity (Krapivin and Varotsos, 2008).

Most of the modeling estimates of the basic components of the carbon cycle show that its maximum supply is concentrated in the World Ocean and its minimum in the atmosphere. It should be stressed, however, that the natural processes that determine the global carbon cycle dynamics obey various time scales. For example, the amounts of the dead organic matter that is buried in the the oceans bottom, exhibit temporal scales of the order of $10^{2}-10^{3}$ years, while the biological components of the carbon cycle on land, appear a temporal variability of several decades. Consequently, the consideration of the above-mentioned temporal variability of the biospheric carbon cycle is of great importance. Keeping this in mind in the relevant modeling, it is equally important to consider the temporal variability of the complete atmospheric mixing that can last up to a couple of years (Kondratyev et al., 2004).

Additionally the spatial variability in the atmospheric $\mathrm{CO}_{2}$ concentrations is of crucial importance. Routine observations obtained at different stations revealed that the $\mathrm{CO}_{2}$ field appears substantial discrepancies in the annual variability. More specifically, the amplitude of the $\mathrm{CO}_{2}$ variation ranges from $10 \mathrm{ppm}$ over Antarctica to $10-15 \mathrm{ppm}$ at the near Arctic region. This heterogeneity is attributed to the presence of large vegetation communities in the northern hemisphere $(\mathrm{NH})$ which exhibits substantial seasonal photosynthesis (Kondratyev et al., 2004).

In this context, the latitudinal distribution of $\mathrm{CO}_{2}$ in the atmosphere displays non-linear character (Varotsos, 2005; Varotsos and Kirk-Davidoff, 2006; Varotsos et al., 2012, 2013). The increased $\mathrm{CO}_{2}$ content in the atmosphere of the $\mathrm{NH}$ is closely linked to both the direct $\mathrm{CO}_{2}$ anthropogenic emissions and the vegetation cover. For instance, it is considered that the organic fuel burning results in almost $90 \%$ of the total emissions of carbon which is located in the latitudinal belt $30^{\circ} \mathrm{N}-60^{\circ} \mathrm{N}$ (Kondratyev et al., 2004).

As previously stated, an important component of the wellknown schematic pathways of the carbon cycle on a global basis 
is the distribution of carbon fluxes into the World Ocean. In this connection, there is now the required information to select several oceanic layers in various depths to distinguish the spatial heterogeneities. In this regard, most of the relevant studies assume two or three layers in the vertical structure of the oceans considering both the photic and deep layers. More recent schemes of the

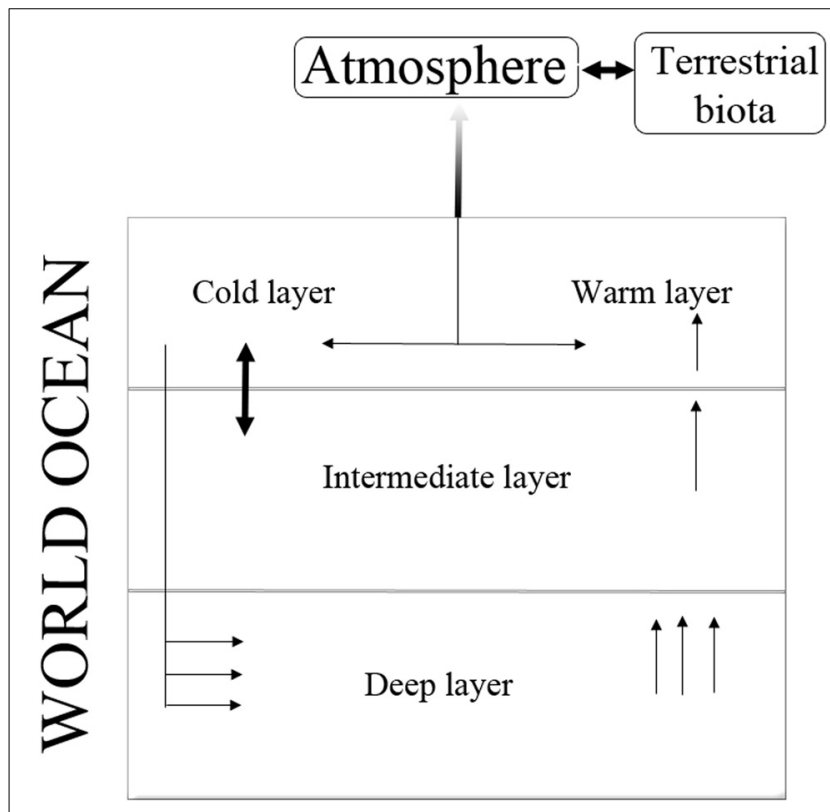

FIGURE 1 | Schematic pathways of the carbon fluxes in the modeling algorithms that consider various depths in the World Ocean.

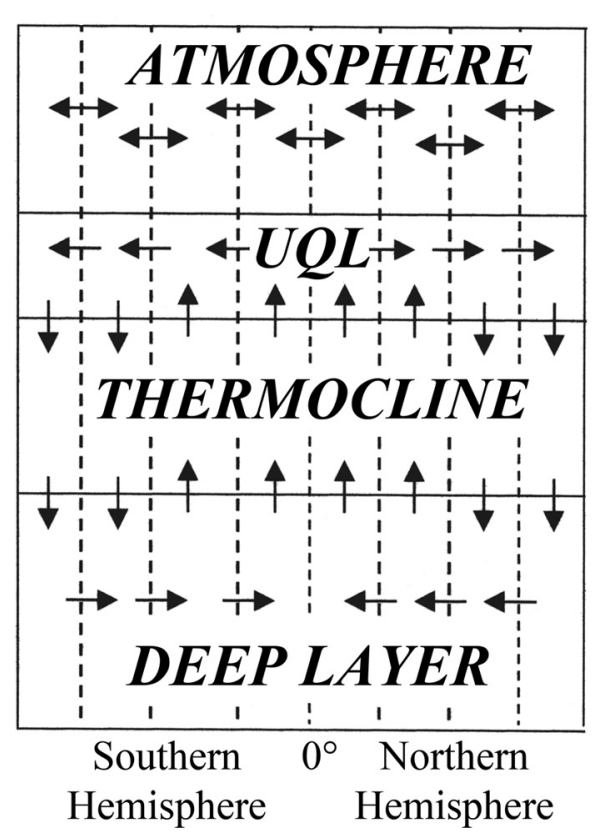

FIGURE 2 | Schematic pathways of the circulation in the World Ocean for the mapping of carbon cycles considering the upper quasi-homogeneous layer (UQL). global carbon cycle take into account all the above-mentioned heterogeneities, increasing thus considerably the fidelity of the relevant modeling algorithms. Two of the widely used schematic pathways are shown in Figures 1, 2 (Kondratyev et al., 2004).

As mentioned above, the process of exchange of $\mathrm{CO}_{2}$ in the atmosphere-ocean borders reveals the contribution of the World Ocean to the global cycle of $\mathrm{CO}_{2}$. The extent of this exchange is expressed by the dynamic characteristics of the turbulent layers of water and air near the interface of the ocean and the atmosphere. In this context, numerous physical schemes take into account the sea wave formation, as well as formation of foam and various films. Specifically, these schemes consider that $\mathrm{CO}_{2}$ either dissolves into the ocean releasing the $\mathrm{CO}_{2}$ that is required for photosynthesis, or enters the atmosphere. The cause of this twofold process in the atmosphere-ocean boundary is the relative difference between the partial pressures of $\mathrm{CO}_{2}$ dissolved in the water and that of contained within the atmosphere. Indeed, this oriented $\mathrm{CO}_{2}$ transport at the frontier "air-water" is much more complex and therefore its investigation postulates expensive in-field campaigns and a detailed classification of both synoptic and geographical conditions of the oceans surface (Ayers, 2005; Krapivin and Varotsos, 2008).

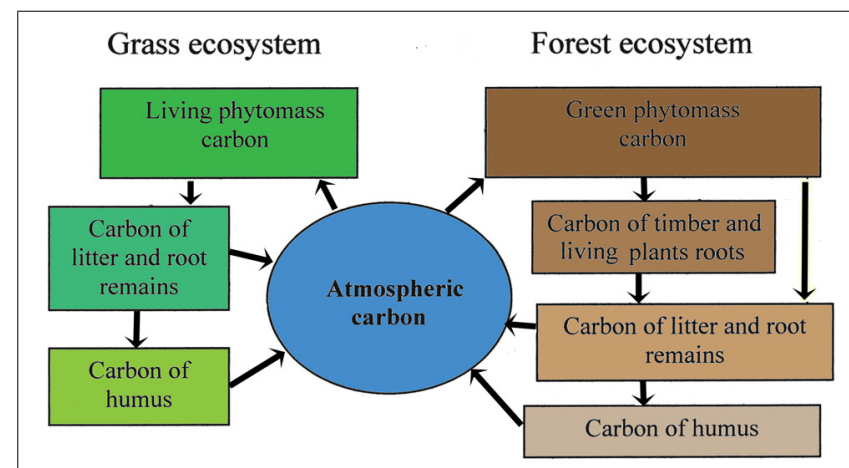

FIGURE 3 | The flow-chart of the carbon fluxes interplay in the system atmosphere-plant-soil with the grass and forest ecosystems.

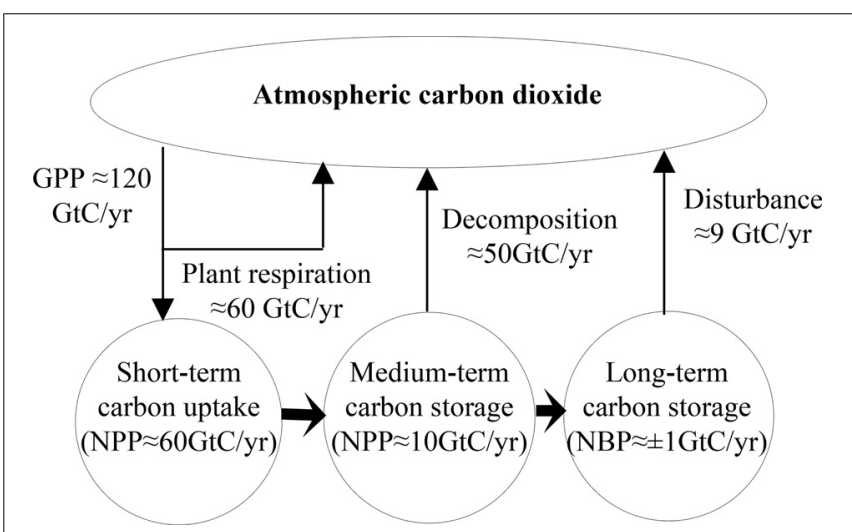

FIGURE 4 | The scheme of the global carbon cycle (GPP, gross primary productivity; NPP, net primary productivity; NEP, net ecosystem productivity; NBP, net biome productivity; GtC, gigatons of carbon $=10^{9}$ metric tones of $\mathrm{C}$ ). 
In the study of the global carbon cycles the emphasis is placed on the role of the surface ecosystems. In the process of photosynthesis, plants absorb $\mathrm{CO}_{2}$ and, conversely, the decomposion of dead plants causes the emission of $\mathrm{CO}_{2}$ into the atmosphere. Thus, between the living and dead organic matter of the land biosphere and the atmosphere a continuous exchange of $\mathrm{CO}_{2}$ is taking place. Many conceptual schematic diagrams illustrate this exchange and serve as background for modeling algorithms of the global carbon cycle. Figures 3, 4 show two examples of such diagrams (Kondratyev et al., 2004).

Of course, the correct assessment of the carbon fluxes in the terrestrial biosphere involves both the detailed quantization of the types of soil-plant formations and the correct assessment of the parameterization of the biocenotic processes. For this approach, the knowledge of the following parameters would be available: areas of vegetation and soils, data of the vital functions of soil microorganisms, and technologies of an operational monitoring of landscapes. However, the accurate figures about the details of the soil-plant formations are not available so far, and therefore the current accuracy of the estimates of carbon fluxes is poor (Kondratyev et al., 2004).

To overcome this difficulty, a modeling scheme of carbon cycle is required, which would describe the ranking of the important biospheric components and the possible pathways of transformation of carbon. As an example, an indicative schematic

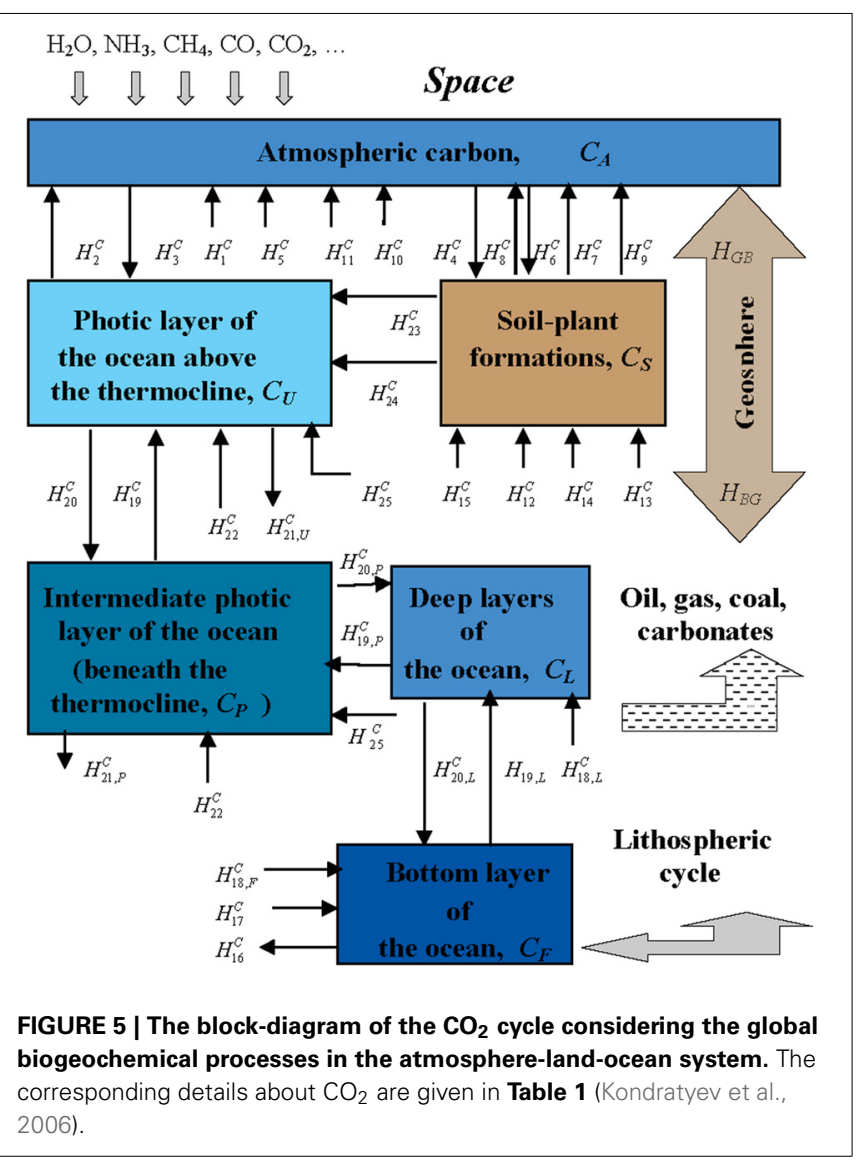

diagram of carbon flux for the required modeling assessment is given in Figure 5 and in Table 1. The employment of this model allows numerical experiments for the optimal spatial quantization, considering comparative estimates of the constituents involved and thus to successively approach required quantization (Kondratyev et al., 2004).

Table 1 | Model of global $\mathrm{CO}_{2}$ cycle (MGCDC): Carbon reservoirs and fluxes and their average estimates considering the global processes illustrated in Figure 5 (Kondratyev et al., 2006).

\begin{tabular}{lcc}
\hline $\mathrm{CO}_{2}$ reservoirs & $\begin{array}{c}\text { Identifier in } \\
\text { and fluxes }\end{array}$ & $\begin{array}{c}\text { Average estimate } \\
\text { the model reservoir }\left(10^{9} \mathrm{t}\right)\end{array}$ \\
& $\begin{array}{c}\text { and flux }\left(10^{9} \mathrm{t} / \text { year }\right) \\
\text { and }\end{array}$
\end{tabular}

\begin{tabular}{llc}
\hline CARBON & & \\
Atmosphere & $C_{A}$ & $650-750$ \\
Photic layer of the ocean & $C_{U}$ & $580-1020$ \\
Deep layers of the ocean & $C_{L}$ & $34,500-37,890$ \\
Soil humus & $C_{S}$ & $1500-3000$ \\
EMISSION DUE TO BURNING & & \\
$\quad$ Vegetation & $H_{8}^{C}$ & 6.9 \\
$\quad$ Fossil fuel & $H_{1}^{C}$ & 3.6 \\
Desorption & $H_{2}^{C}$ & 97.08 \\
Sorption & $H_{3}^{C}$ & 100 \\
Rock weathering & $H_{4}^{C}$ & 0.04 \\
Volcanic emanations & $H_{5}^{C}$ & 2.7 \\
Assimilation by land & $H_{6}^{C}$ & 224.4 \\
vegetation & &
\end{tabular}

vegetation

\begin{tabular}{|c|c|c|}
\hline \multicolumn{3}{|l|}{ RESPIRATION } \\
\hline Plants & $H_{7}^{C}$ & $50-59.3$ \\
\hline People & $H_{10}^{C}$ & 0.7 \\
\hline Animals & $H_{11}^{C}$ & 4.1 \\
\hline \multicolumn{3}{|l|}{ EMISSION } \\
\hline Decomposed soil humus & $H_{9}^{C}$ & 139.5 \\
\hline Plants' roots & $H_{15}^{C}$ & 56.1 \\
\hline \multicolumn{3}{|l|}{ VITAL FUNCTIONS } \\
\hline Population & $H_{12}^{C}$ & 0.3 \\
\hline Animals & $H_{13}^{C}$ & 3.1 \\
\hline Vegetation decay & $H_{14}^{C}$ & $31.5-50$ \\
\hline $\begin{array}{l}\text { Sedimentation to bottom } \\
\text { deposits }\end{array}$ & $H_{16}^{C}$ & $0.1-0.2$ \\
\hline Solution of marine sediments & $H_{17}^{C}$ & 0.1 \\
\hline \multicolumn{3}{|c|}{ DECOMPOSITION OF DETRITUS } \\
\hline Photic layer & $H_{22}^{C}$ & 35 \\
\hline Deep layers of the ocean & $H_{18}^{C}$ & 5 \\
\hline Uplifting with deep waters & $H_{19}^{C}$ & 45 \\
\hline $\begin{array}{l}\text { Lowering with surface waters } \\
\text { and due to gravitational } \\
\text { sedimentation }\end{array}$ & $H_{20}^{C}$ & 40 \\
\hline Photosynthesis & $H_{21}^{C}$ & 69 \\
\hline Underground sink & $H_{23}^{C}$ & 0.5 \\
\hline Surface sink & $H_{24}^{C}$ & $0.5-0.6$ \\
\hline $\begin{array}{l}\text { Breathing of living organisms } \\
\text { in the ocean }\end{array}$ & $H_{25}^{C}$ & 25 \\
\hline Geospheric sink of carbon & $H_{B G}$ & 70 \\
\hline Geospheric source of carbon & $H_{G B}$ & 17 \\
\hline
\end{tabular}




\section{Atmosphere}
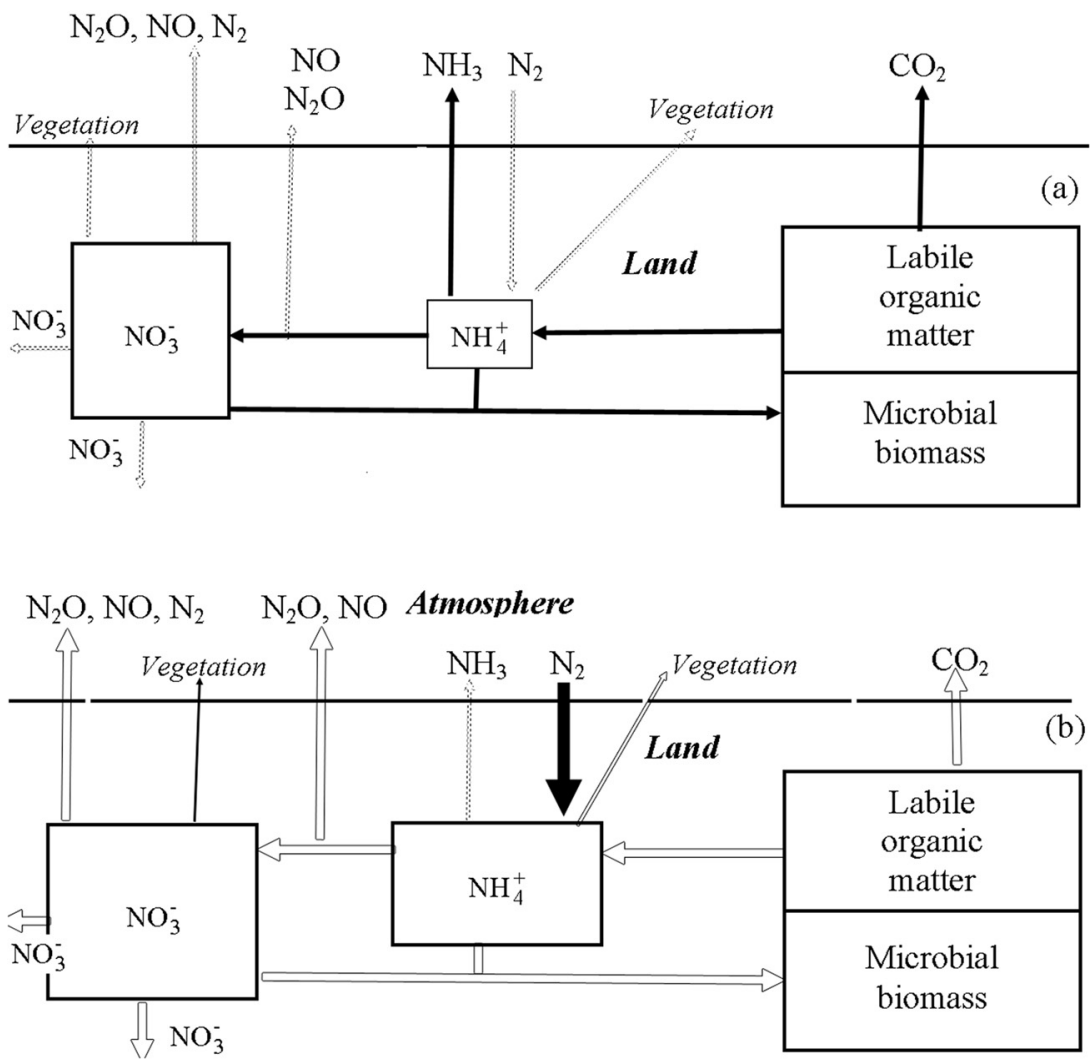

FIGURE 6 | Block-diagram of biogeochemical cycles of $\mathbf{C}$ and $\mathbf{N}$ in the water-limited ecosystems (Krapivin and Varotsos, 2008). (A) Dry season; (B) wet season.

\section{MODELING SCHEMES OF THE NITROGEN CYCLE IN NATURE}

It is a truism that nitrogen is one of the basic nutrient elements in nature. That is why its global cycle is of great interest. According to the current understanding its cycle exhibits a composit structure of several processes of its compounds that are mainly formed due to water migration and plethora of relevant atmospheric processes (Varotsos et al., 1998; Akimoto, 2003; Wilson et al., 2007; Van der A et al., 2008; Tzanis et al., 2009, 2011; Xue et al., 2010). The known nitrogen cycle is subject to intense anthropogenic forcings generated by the interaction of the nitrogen cycle both directly and through the influence on the related processes (Krapivin and Varotsos, 2008). Therefore, the development of a reliable model of the nitrogen cycle in nature should be based on the consideration of the whole complex natural processes and those initiated by human activities. Figures 6, 7 illustrate a schematic pattern of the main supplies and fluxes of nitrogen.

It is generally recognized that the natural sources of nitrogen oxides are strongly related to bacteria, volcanic eruptions, and several atmospheric phenomena, like the lightning discharges. More specifically, the biogeochemical cycle of nitrogen includes among others, fixation, mineralization, nitrification, assimilation, and dissimilation mechanisms that have been investigated in many studies (e.g., Krapivin and Varotsos, 2008). Their complexity is determined by the rates of transformation of the nitrogen compounds their supplies, etc.

It is well-known that nitrogen participates in the biospheric processes with a complex structure of fluxes that are characterized by a hierarchical sequence of cycles in the biosphere. For example, starting from the atmosphere, nitrogen enters the microorganisms, migrating successively to soil, higher plants, animals, and humans. Then nitrogen returns back to the soil due to the death of living organisms. From the soil nitrogen, is either consumed by plants and living organisms or is emitted into the atmosphere. Approximately the same pattern is observed in the hydrosphere. The feature of the above-mentioned cycles is their openness to the available nitrogen removal processes from the biospheric balance into rocks, from which returns much slower. Given the nature of the nitrogen cycle in the biosphere and its reservoir structure, it is quite possible to formulate a global scheme of nitrogen fluxes (Krapivin and Kelley, 2009).

To simplify the scheme of the calculation of nitrogen fluxes presented in Figure 7 (bottom), the advection processes in the balance equations of nitrogen cycle can be illustrated by a superposition of the fluxes $H_{14}^{N}$ and $H_{15}^{N}$. However, for the development of such a model by employing these equations several corrections are necessary. Therefore, the estimates of the fluxes $H_{i}^{N}$ given in Table 2 for their consideration in the GIMS should be corrected 


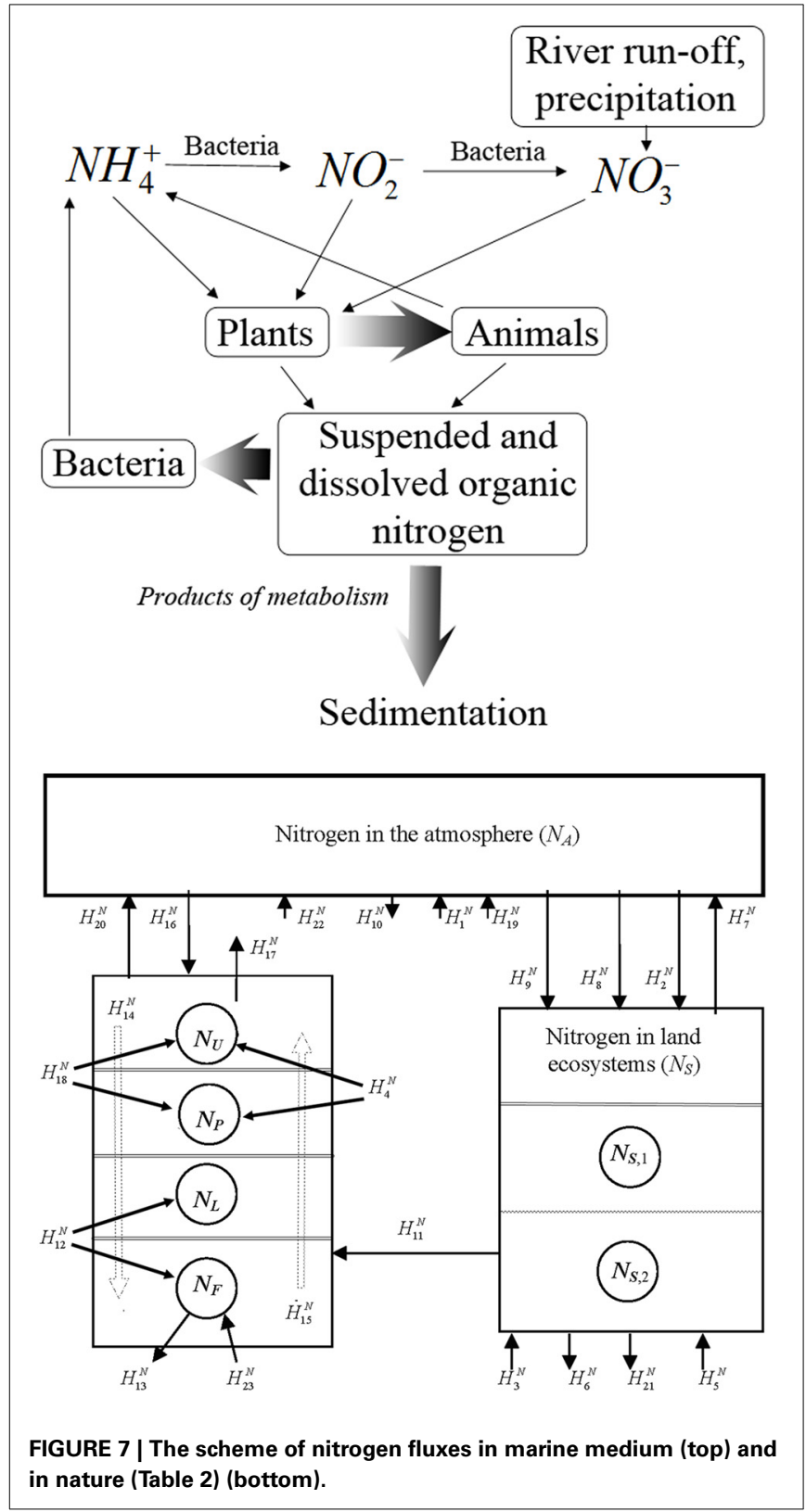

following this criterion. Detailed description of the nitrogen cycle as unit of the GIMS was given by Krapivin and Varotsos (2008).

\section{CONCLUSIONS}

The problem of reliable modeling of biochemical cycles that control greenhouse effect, bioproductivity and environmental quality, is far from being solved. The correlations between biochemical cycles and the many activities of human society show that a deeper knowledge of the mechanisms involved must be obtained especially through the observational data of the biochemical processes. In this connection, the reliable assessment of the role that the biochemical cycles play in global ecodynamics is crucial considering that these are the main indicators of sustainable development (Kondratyev et al., 1995, 2006; Nitu et al., 2013a,b). As an example, in the formation of the carbon cycle
Table 2 | Characteristics of reservoirs and fluxes of nitrogen in the biosphere (Figure 7 bottom).

\begin{tabular}{|c|c|c|}
\hline $\begin{array}{l}\text { Reservoirs (Gt) and fluxes } \\
\left(10^{6} \mathrm{t} / \text { year }\right)\end{array}$ & Identifier & Estimate \\
\hline \multicolumn{3}{|l|}{ NITROGEN SUPPLIES } \\
\hline Atmosphere & $N_{A}$ & $39.10^{5}$ \\
\hline Soil & $N_{S}$ & 280 \\
\hline $\begin{array}{l}\text { Photic and intermediate } \\
\text { layer of the ocean }\end{array}$ & $N_{U}+N_{P}$ & 2800 \\
\hline $\begin{array}{l}\text { Deep and bottom layer of } \\
\text { the ocean }\end{array}$ & $N_{L}+N_{F}$ & 36400 \\
\hline $\begin{array}{l}\text { Natural sources of the } \\
\text { hydrosphere }\end{array}$ & $H_{1}^{N}$ & 0.392 \\
\hline \multicolumn{3}{|c|}{ TECHNOGENIC ACCUMULATION } \\
\hline Fuel burning & $H_{2}^{N}$ & 22.8 \\
\hline Fertilizers production & $H_{9}^{N}$ & 41.8 \\
\hline \multicolumn{3}{|c|}{ INPUT DUE TO DEAD ORGANISMS } \\
\hline On land & $H_{3}^{N}$ & 42.2 \\
\hline $\begin{array}{l}\text { In upper layers of the World } \\
\text { Ocean }\end{array}$ & $H_{18}^{N}$ & 5 \\
\hline In deep layers of the World & $H_{12}^{N}$ & 7.8 \\
\hline
\end{tabular}

Ocean

\section{INPUT DUE TO ORGANISMS FUNCTIONING}

\begin{tabular}{|c|c|c|}
\hline On land & $H_{5}^{N}$ & 0.1 \\
\hline In the World Ocean & $H_{4}^{N}$ & 0.3 \\
\hline \multicolumn{3}{|l|}{ BIOLOGICAL FIXATION } \\
\hline On land & $H_{6}^{N}$ & 20.3 \\
\hline In the World Ocean & $H_{17}^{N}$ & 10 \\
\hline In the atmosphere & $H_{10}^{N}$ & 40 \\
\hline \multicolumn{3}{|l|}{ DENITRIFICATION } \\
\hline On land & $H_{7}^{N}$ & 52 \\
\hline In the World Ocean & $H_{20}^{N}$ & 49.8 \\
\hline \multicolumn{3}{|l|}{ ATMOSPHERIC FIXATION } \\
\hline Over land & $H_{8}^{N}$ & 4 \\
\hline Over the World Ocean & $H_{16}^{N}$ & 3.6 \\
\hline $\begin{array}{l}\text { Run-off from land into the } \\
\text { World Ocean }\end{array}$ & $H_{11}^{N}$ & 38.6 \\
\hline Precipitation & $H_{13}^{N}$ & 0.5 \\
\hline $\begin{array}{l}\text { Vertical exchange processes } \\
\text { in the oceans }\end{array}$ & $H_{14}^{N}$ & 0.2 \\
\hline Descending & $H_{15}^{N}$ & 7.5 \\
\hline Lifting & $H_{19}^{N}$ & 15 \\
\hline \multicolumn{3}{|c|}{ ANTHROPOGENIC EMISSIONS TO THE ATMOSPHERE } \\
\hline $\begin{array}{l}\text { Removal of nitrogen from the } \\
\text { cycle due to sedimentation }\end{array}$ & $H_{21}^{N}$ & 0.2 \\
\hline $\begin{array}{l}\text { Input of nitrogen to the } \\
\text { atmosphere during rocks } \\
\text { weathering }\end{array}$ & $H_{22}^{N}$ & 0.217 \\
\hline $\begin{array}{l}\text { Input of nitrogen to the water } \\
\text { medium with dissolving }\end{array}$ & $H_{23}^{N}$ & 0.091 \\
\hline
\end{tabular}

medium with dissolving

sediments

the soil-plants and the World Ocean play a crucial role which may be assessed by the global carbon cycle model. This model considers different scenarios with geographical grids greater than the needed ones for a reliable assessment. 


\section{REFERENCES}

Akimoto, H. (2003). Global air quality and pollution. Science 302, 1716-1719. doi: 10.1126/science. 1092666

Amann, M., Bertok, I., Borken-Kleefeld, J., Cofala, J., Heyes, C., Höglund-Isaksson, L., et al. (2011). Cost-effective control of air quality and greenhouse gases in Europe: modeling and policy applications. Environ. Model. Software 26, 1489-1501. doi: 10.1016/j.envsoft.2011.07.012

Ayers, G. (2005). Air pollution and climate change: has air pollution suppressed rainfall over Australia? Clean Air Environ. Qual. 39, 51.

Kondratyev, K. Y., Krapivin, V. F., Savinykh, V. P., and Varotsos, C. A. (2004). Global Ecodynamic: A Multidimensional Analysis. Chichester: Springer/Praxis. doi: 10.1007/978-3-642-18636-3

Kondratyev, K. Y., Krapivin, V. F., and Varotsos, C. A. (2006). Natural Disasters as Interactive Components of Global Ecodynamics. Chichester: Springer/ Praxis.

Kondratyev, K. Y., Pokrovsky, O. M., and Varotsos, C. A. (1995). Atmospheric ozone trends and other factors of surface ultraviolet radiation variability. Environ. Conserv. 22, 259-261. doi: 10.1017/S0376892900010663

Kondratyev, K. Y., and Varotsos, C. (1995). Atmospheric greenhouse effect in the context of global climate change. Il Nuovo Cimento C, 18, 123-151. doi: 10.1007/BF02512015

Krapivin, V. F., and Kelley, J. J. (2009). "Model-based method for the assessment of global change in the nature-society system," in Global Climatology and Ecodynamics eds A. P. Cracknell, V. Krapivin, and C. Varotsos (Chichester: Springer Praxis), 133-183.

Krapivin, V. F., and Varotsos, C. A. (2008). Biogeochemical Cycles in Globalization and Sustainable Development. Chichester: Springer/Praxis.

Nitu, C., Krapivin, V. F., Soldatov, V. Y., and Dobrescu, A. (2013a). "A device to measure the geophysical and hydrophysical parameters," in Proceedings of the 19th International Conference on Control Systems and Computer Science - CSCS19 (Bucharest), 281-284.

Nitu, C., Krapivin, V. F., Varotsos, C. A., Cracknell, A. P., Soldatov, V. Y., and Dumitrascu, A. (2013b). "An effective tool for the tropical cyclones monitoring," in Proceedings of the 19th International Conference on Control Systems and Computer Science-CSCS19 (Bucharest), 276-280.

Tzanis, C., Varotsos, C., Christodoulakis, J., Tidblad, J., Ferm, M., Ionescu, A., et al. (2011). On the corrosion and soiling effects on materials by air pollution in Athens, Greece. Atmos. Chem. Phys. 11, 12039-12048. doi: 10.5194/acp-1112039-2011

Tzanis, C., Varotsos, C., Ferm, M., Christodoulakis, J., Assimakopoulos, M. N., and Efthymiou, C. (2009). Nitric acid and particulate matter measurements at Athens, Greece, in connection with corrosion studies. Atmos. Chem. Phys. 9, 8309-8316. doi: 10.5194/acp-9-8309-2009
Van der A, R. J., Eskes, H. J., Boersma, K. F., van Noije, T. P. C., Van Roozendael, M., De Smedt, I., et al. (2008). Trends, seasonal variability and dominant NOx source derived from a ten year record of $\mathrm{NO}_{2}$ measured from space. J. Geoph. Res. 113, D04302. doi: 10.1029/2007JD009021

Varotsos, C. (2005). Power-law correlations in column ozone over Antarctica. Int. J. Rem. Sens. 26, 3333-3342. doi: 10.1080/01431160500076111

Varotsos, C. A., Chronopoulos, G. J., Cracknell, A. P., Johnson, B. E., Katsambas, A., and Philippou, A. (1998). Total ozone and solar ultraviolet radiation, as derived from satellite and ground-based instrumentation at Dundee, Scotland. Int. J. Rem. Sens. 19, 3301-3305. doi: 10.1080/014311698213984

Varotsos, C. A., Melnikova, I., Efstathiou, M. N., and Tzanis, C. (2013). 1/f noise in the UV solar spectral irradiance. Theor. Appl. Clim. 111, 641-648. doi: 10.1007/s00704-012-0697-8

Varotsos, C., and Kirk-Davidoff, D. (2006). Long-memory processes in ozone and temperature variations at the region 60 S-60 N. Atmos. Chem. Phys. 6, 4093-4100. doi: 10.5194/acp-6-4093-2006

Varotsos, C., Ondov, J., Tzanis, C., Öztürk, F., Nelson, M., Ke, H., et al. (2012). An observational study of the atmospheric ultra-fine particle dynamics. Atmos. Environ. 59, 312-319. doi: 10.1016/j.atmosenv.2012.05.015

Wilson, N., Edwards, R., Maher, A., Näthe, J., and Jalali, R. (2007). National smoke free law in New Zealand improves air quality inside bars, pubs and restaurants. BMC Public Health 7:85. doi: 10.1186/1471-2458-7-85

Xue, Y., Ai, J., Wan, W., Li, Y., Wang, Y., Guang, J., et al. (2010). Workload and task management of grid- enabled quantitative aerosol retrieval from remotely-sensed data. AIP Conf. Proc. Future Gen. Comp. Syst. 20, 590-598. doi: 10.1016/j.future.2009.11.003

Conflict of Interest Statement: The authors declare that the research was conducted in the absence of any commercial or financial relationships that could be construed as a potential conflict of interest.

Received: 25 February 2014; paper pending published: 17 March 2014; accepted: 03 April 2014; published online: 23 April 2014.

Citation: Varotsos CA, Krapivin VF and Soldatov VY (2014) Modeling the carbon and nitrogen cycles. Front. Environ. Sci. 2:8. doi: 10.3389/fenvs.2014.00008

This article was submitted to Air Pollution, a section of the journal Frontiers in Environmental Science.

Copyright (c) 2014 Varotsos, Krapivin and Soldatov. This is an open-access article distributed under the terms of the Creative Commons Attribution License (CC BY). The use, distribution or reproduction in other forums is permitted, provided the original author(s) or licensor are credited and that the original publication in this journal is cited, in accordance with accepted academic practice. No use, distribution or reproduction is permitted which does not comply with these terms. 